Goldschmidt 2021 Abstract

https://doi.org/10.7185/gold2021.4751

\section{Antimony isotopic fractionation in the environment: first insights from theoritical and experimental investigations}

\author{
COLIN FERRARI ${ }^{1}$, ELÉONORE RESONGLES ${ }^{1}$, CORINNE
} CASIOT $^{1}$, RÉMI FREYDIER ${ }^{1}$ AND MERLIN MÉHEUT ${ }^{2}$

${ }^{1}$ Hydrosciences Montpellier, Université de Montpellier, CNRS, IRD

${ }^{2}$ CNRS Géosciences Environment Toulouse, Université de Toulouse, UPS, IRD, CNES

Presenting Author: colin.ferrari@umontpellier.fr

Antimony is a toxic metalloid commonly found at high concentrations in sulfide mining environments. Yet its environmental cycling is largely unknown. Antimony stable isotopes $\left({ }^{121} \mathrm{Sb}\right.$ and $\left.{ }^{123} \mathrm{Sb}\right)$ are promising geochemical tracers. However, very little is known about $\mathrm{Sb}$ isotopic fractionation occurring during key geochemical processes controlling the mobility of $\mathrm{Sb}$ in surface environments (e.g. redox reactions, adsorption...), thus hampering a proper interpretation of $\mathrm{Sb}$ isotopic signatures measured in the environment.

In this contribution, we present preliminary results obtained from complementary theoretical and experimental approaches carried out to characterize mass-dependent $\mathrm{Sb}$ isotopic fractionation associated with some of these processes.

On one hand, first-principle calculations based on density functional theory (DFT) were carried out to estimate equilibrium fractionation factors between antimony minerals representative of $\mathrm{Sb}$ primary ore and secondary phases commonly found in mining-impacted environments (i.e. stibnite, valentinite, cervantite). Modeling was performed using Quantum Espresso software to calculate mineral lattices parameters, vibrational frequencies and isotopic fractionation factors. Computed data were compared with published experimental data (structural data, Raman spectroscopy) to ensure the validity of the method. The results predicted that cervantite $\left(\mathrm{Sb}^{\mathrm{III}} \mathrm{Sb}^{\mathrm{V}} \mathrm{O}_{4}\right)$ and valentinite $\left(\mathrm{Sb}_{2} \mathrm{O}_{3}\right)$ were isotopically heavier compared to stibnite $\left(\mathrm{Sb}_{2} \mathrm{~S}_{3}\right)$ by $\sim 1.6$ and $\sim 1.0 \%$ at $20{ }^{\circ} \mathrm{C}$, respectively, showing the influence of $\mathrm{Sb}$ ligand ( $\mathrm{Sb}-\mathrm{O}$ vs $\mathrm{Sb}-\mathrm{S}$ bond) and $\mathrm{Sb}$ redox state $\left(\mathrm{Sb}^{\mathrm{V}}\right.$ vs $\left.\mathrm{Sb}^{\mathrm{III}}\right)$ on $\mathrm{Sb}$ isotopic variations.

On the other hand, $\mathrm{Sb}$ isotopic fractionation was experimentally determined during adsorption of $\mathrm{Sb}^{\mathrm{V}}$ onto an iron oxyhydroxide (ferrihydrite) which represents an important process limiting Sb mobility in surface waters. Adsorption onto synthetic ferrihydrite was carried out at different $\mathrm{pH}$ and $\mathrm{Sb}$ :ferrihydrite ratios at $20^{\circ} \mathrm{C}$. Isotopic composition $\left(\delta^{123} \mathrm{Sb}\right)$ was determined in the dissolved and solid phases by HG-MC-ICPMS [1]. Antimony light isotope was preferentially adsorbed onto ferrihydrite, leaving the solution isotopically heavier $\left(\Delta^{123} \mathrm{Sb}_{\text {solution-solid }}=0.35 \pm 0.08 \%\right.$ ). The data can be explained by a closed-system model, suggesting that fractionation resulted from an equilibrium exchange between dissolved and adsorbed $\mathrm{Sb}$.

These results provide a preliminary basis to interpret isotopic variations observed during the transport of $\mathrm{Sb}$ from its primary sources to contaminated environments.

[5] Ferrari et al. (2021). JAAS, in press. 